\title{
An unusual pedunculated polyp of the transverse colon associated with schistosomiasis
}

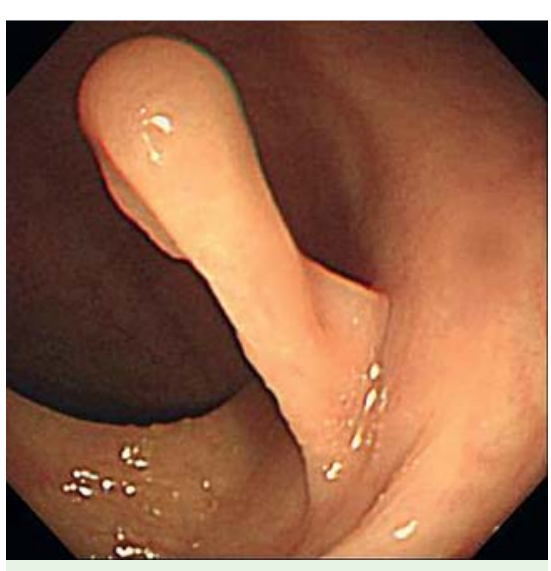

Fig. 1 Colonoscopy showing a pedunculated polyp ( $20 \mathrm{~mm}$ long, $6 \mathrm{~mm}$ wide) in the transverse colon.

We report here a rare case of a pedunculated, inflammatory polyp of the transverse colon associated with schistosomiasis, which was diagnosed and treated by colonoscopy.

A 48-year-old woman presented to the emergency department after an episode of painless bloody stool. She had had a similar episode 2 months previously. Her history revealed no change in appetite and body weight, gastroduodenal ulcers, or hemorrhoids. She was afebrile on admission. The physical examination showed mild epigastric tenderness, but a digital examination showed no remarkable findings. Laboratory data showed white blood count $8.4 \times 10^{9} / \mathrm{L}$, alkaline phosphatase $77 \mathrm{U} / \mathrm{L}$, and normal levels of tumor markers such as carcinoembryonic antigen and carbohydrate antigen 19-9. A plain radiograph of the abdomen showed increased bowel gas pattern in the central abdomen. Colonoscopy revealed a pedunculated polyp, about $20 \mathrm{~mm}$ in length and $6 \mathrm{~mm}$ in diameter, in the transverse colon ( $\bullet$ Fig. 1). As the polyp was thought to be an adenoma, it was removed by endoscopic mucosal resection. Histopathological examination of the specimen revealed calcified schistosomal ova surrounded by prominent eosinophilic infiltrates in the
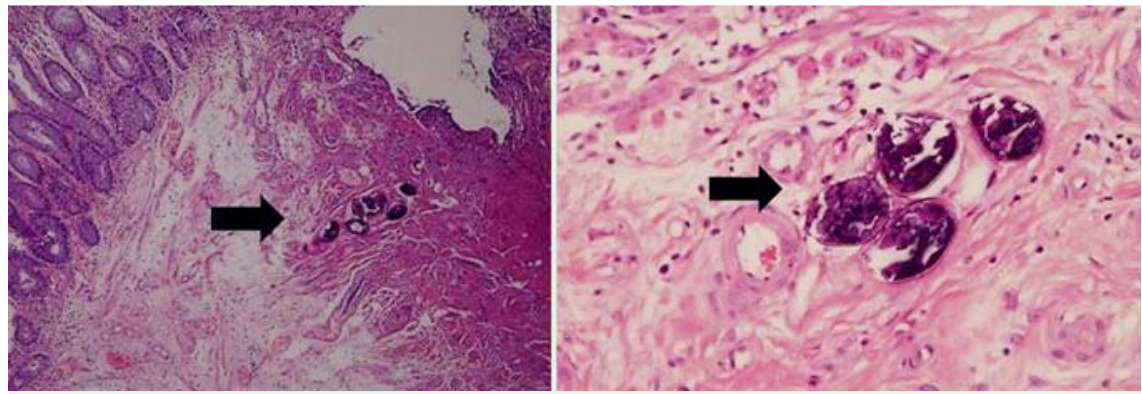

Fig. 2 Histopathological section showing calcified schistosomal ova surrounded by prominent eosinophilic infiltrates in the submucosal layer.

submucosal layer ( $\bullet$ Fig. 2). The patient was treated with praziquantel $(20 \mathrm{mg} / \mathrm{kg})$ with progressive clinical resolution of the bloody stool.

Colonic schistosomiasis is defined as a specific acute or chronic inflammatory reaction to Schistosoma ova, which are deposited mainly in the colorectal mucosa [1]. Worms trapped in the submucosa produce ova that stimulate an intense tissue reaction that further leads to development of polyposis and occasionally pericolic masses [2]. Schistosomal colonic polyps mainly occur in the distal colon in men living in heavily endemic areas and the presenting symptoms are bloody diarrhea, abdominal pain, and rectal bleeding [3]. Although nonspecific, colonoscopy may provide valuable information in the diagnosis of colonic schistosomiasis, such as edematous, congestive mucosa and petechial hemorrhages in patients with acute schistosomal colitis, and a dense vascular mesh with more close-set, flat or elevated, yellow nodules and polyps, and intestinal stricture in patients with chronic schistosomal colitis [4]. To achieve complete symptom relief and prevent complications, colonoscopic polypectomy may be required along with medical therapy [5].

\section{Competing interests: None}

Endoscopy_UCTN_Code_CCL_1AD_2AC Endoscopy_UCTN_Code_CCL_1AD_2AZ
C. T. Lin, C. Y. Chen, S. W. Jao, C. C. Wu Division of Colon and Rectal Surgery, Department of Surgery, Tri-Service General Hospital, National Defense Medical Center, Taipei, Taiwan, Republic of China

\section{References}

1 Yosry A. Schistosomiasis and neoplasia. Contrib Microbiol 2006; 13: $81-100$

2 Scrimgeour EM, Daar AS. Schistosomiasis: clinical relevance to surgeons in Australia and diagnostic update. Aust N Z J Surg 2000; 70: 157-161

3 El-Garem AA. Schistosomiasis. Digestion 1998; 59: 589-605

4 Ohmae H, Sy OS, Chigusa Y, Portillo GP. Imaging diagnosis of schistosomiasis japonica the use in Japan and application for field study in the present endemic area. Parasitol Int 2003; 52: 385-393

5 Hussein AM, Medany S, Abou El Magd AM et al. Multiple endoscopic polypectomies for schistosomal polyposis of the colon. Lancet 1983; $1: 673-674$

\section{Bibliography}

DOI $10.1055 / \mathrm{s}-0029-1244142$

Endoscopy 2010; 42: E160

(c) Georg Thieme Verlag KG Stuttgart · New York . ISSN 0013-726X

\section{Corresponding author}

\section{C. Wu}

Division of Colon and Rectal Surgery

Department of Surgery

Tri-Service General Hospital

No. 325 Cheng-Kung Road

Sec 2 Neihu 114

Taipei

Taiwan

Fax: 886-2-87927372

aarondakimo@yahoo.com.tw 